\title{
Mireille Calle-Gruber, Les Triptyques de Claude Simon ou l'art du montage
}

\section{Gian Luigi Di Bernardini}

\section{(2) OpenEdition}

\section{Journals}

\section{Edizione digitale}

URL: http://journals.openedition.org/studifrancesi/7030

DOI: ERREUR PDO dans/localdata/www-bin/Core/Core/Db/Db.class.php L.34 : SQLSTATE[HYO0O]

[2006] MySQL server has gone away

ISSN: 2421-5856

\section{Editore}

Rosenberg \& Sellier

\section{Edizione cartacea}

Data di pubblicazione: 1 septembre 2010

Paginazione: 406-407

ISSN: 0039-2944

Notizia bibliografica digitale

Gian Luigi Di Bernardini, «Mireille Calle-Gruber, Les Triptyques de Claude Simon ou l'art du montage», Studi Francesi [Online], 161 (LIV | II) | 2010, online dal 30 novembre 2015, consultato il 08 janvier 2021. URL: http://journals.openedition.org/studifrancesi/7030; DOI: https://doi.org/10.4000/studifrancesi. 7030

Questo documento è stato generato automaticamente il 8 janvier 2021.

\section{(c) (†) $\ominus$}

Studi Francesi è distribuita con Licenza Creative Commons Attribuzione - Non commerciale - Non opere derivate 4.0 Internazionale. 


\title{
Mireille Calle-Gruber, Les Triptyques de Claude Simon ou l'art du montage
}

\author{
Gian Luigi Di Bernardini
}

\section{NOTIZIA}

MIREILLE CALLE GRUBER, Les Triptyques de Claude Simon ou l'art du montage, Paris, Presses

Sorbonne Nouvelle, 2008, pp. 216.

1 Mireille Calle-Gruber raccoglie in questo agile volume una serie di materiali eterogenei (sceneggiature, corrispondenze, manoscritti, interviste ed altri ancora), per lo più inediti e prodotti tra il 1958 e il 1978, con l'intento dichiarato di accompagnare il lettore nel cammino di avvicinamento al metodo creativo di Claude Simon.

2 A tal riguardo l'autrice sottolinea, già nella propria introduzione Claude Simon la main heureuse (pp. 7-16) l'ampiezza dell'interesse dello scrittore per l'aspetto formale della narrazione romanzesca e filmica. Per questo importante esponente del Nouveau Roman, il concetto di forma è ciò che Calle-Gruber definisce come un «art du montage» (p. 8) riscontrabile, ad esempio nel romanzo, nella messa in evidenza della posizione del narratore rispetto alla diegesi, e, al cinema, nel rapporto tra la posizione della telecamera e la scena. A ciò va aggiunta la cura delle sequenze narrative, trattate (in fase di scrittura) come quadri distaccati, poi associate ad un colore ed infine riassemblate in modo che i diversi colori si ritrovino nella giusta gradazione in tutti i quadri. In questo modo, l'autore può garantire una corretta gestione della presenza di temi e motivi del testo.

3 Le Notes sur Triptyque (pp. 23-26) rappresentano una perfetta illustrazione di questo metodo di scrittura. Claude Simon spiega infatti di aver adottato, per il suo film, il modello del trittico medievale in cui la vita del santo viene ripartita in tre segmenti non necessariamente collegati tra loro tramite il criterio cronologico. Simon costruisce, quindi, l'unità del suo Triptyque «sur une certaine unité plastique [...] de la couleur (en l'occurrence le rouge, le noir et le blanc)» (p. 23). 
4 Da ricollegarsi all'attenzione per l'aspetto morfologico del testo è poi la nozione di credibilità della fiction, non da intendersi come quoziente di adesione del testo (romanzesco o filmico) al reale, bensì come capacità dello scrittore di stabilire rapporti interni al linguaggio utilizzato, come nel già visto esempio dei rimandi al codice coloristico. L'insieme delle tecniche utilizzate da Simon mira, in ultima analisi, alla costante denuncia della fiction in quanto tale e a distruggere, pertanto, gli ultimi residui dell'illusione realista-referenziale, incarnata in primis dalla struttura narrativa cronologica.

5 Tra gli interventi di maggior interesse si può segnalare certamente l'articolo a firma dello stesso Simon, L'inattendu attendu (pp. 19-21) in cui l'autore sottolinea la preminenza del cinema (e in particolar modo di Buñuel e Dali) rispetto alla letteratura nella sua formazione di scrittore, e la conseguente costruzione di un'estetica di natura più visuale che linguistica in senso classico.

6 Il libro è arricchito dalla riproduzione fotografica dei manoscritti e dei plans de montage di Triptyque e di Le Jardin des Plantes.

$7 \quad \mathrm{Al}$ volume è poi allegato un DVD che riproduce due documenti. Il primo è un'intervista svoltasi insieme a Pierre Boulez durante una puntata della storica trasmissione Apostrophes, nel 1981. L'altro è il vero e proprio Triptyques, che è l'insieme di diverse interviste a Claude Simon riguardanti l'arte della scrittura. 